\title{
Diet Modification to Reduce Fecal Excretion of Nitrogen and Phosphorus in Growing-Finishing Pigs
}

\author{
${ }^{1}$ Ondieki Gekara, ${ }^{1}$ Talesha Dokes and ${ }^{2}$ Renita Marshall \\ ${ }^{1}$ Department of Agriculture, University of Arkansas at Pine Bluff, Pine Bluff, Arkansas, US \\ ${ }^{2}$ Agricultural Research and Extension Center, Southern University, Baton Rouge, Louisiana, US
}

Received 2013-08-19, Revised 2013-09-26; Accepted 2013-10-03

\begin{abstract}
An experiment was conducted to determine whether brewers rice can replace all corn in diets for swine and reduce fecal excretion of Nitrogen $(\mathrm{N})$ and Phosphorus $(\mathrm{P})$ without compromising performance and carcass quality of growing-finishing pigs. Sixteen Yorkshire x Duroc x Hampshire crosses (BW = 77 $\pm 2.5 \mathrm{~kg}$ ) were randomly assigned to either corn/soybean meal (CSM; control) or brewers rice/soybean meal (RSM) diet. Both diets were formulated to contain $14 \% \mathrm{CP}$. The RSM pigs had a greater reduction $(\mathrm{p}<0.001)$ in daily fecal loss of $\mathrm{N}\left(0.007\right.$ Vs. $\left.0.011 \mathrm{~kg} \mathrm{pig}^{-1}\right)$ and $\mathrm{P}\left(0.007\right.$ Vs. $\left.0.008 \mathrm{~kg} \mathrm{pig}^{-1}\right)$, lower $(\mathrm{p}<0.001)$ fecal output $(0.171 \mathrm{Vs} .0 .322 \mathrm{~kg}$ $\left.\mathrm{pig}^{-1}\right)$, than CSM pigs. Compared with CSM pigs, RSM pigs gained faster $\left(0.712 \mathrm{Vs} .0 .581 \mathrm{~kg} \mathrm{pig}^{-1}\right.$ per day; $\mathrm{p}<0.01)$ and had better gain to feed ratio $(0.30$ Vs. $0.25 ; \mathrm{p}<0.01)$. Furthermore, RSM pigs had greater $(\mathrm{p}<0.001)$ Apparent Total Tract Digestibility (ATTD; 91.5 Vs. 84.1\%). Diet did not ( $p>0.10)$ affect carcass yield and Loin Eye Area (LEA), however, RSM pigs tended $(\mathrm{p}<0.10)$ to lay more back fat than CSM pigs. In conclusion, brewers rice can replace all corn in diets for growing-finishing pigs, reduce fecal excretion of $\mathrm{N}$ and $\mathrm{P}$, increase pig performance with no effect on carcass quality. Consequently, feeding brewers rice instead of corn may help reduce environmental pollution attributed to excessive fecal excretion of $\mathrm{N}$ and $\mathrm{P}$ in growing-finishing pigs.
\end{abstract}

Keywords: Diet Modification, Fecal Nitrogen, Fecal Phosphorus, Animal Performance, Carcass Quality, Growing-Finishing Pigs

\section{INTRODUCTION}

Swine diets are formulated and balanced to meet daily animal requirements for different nutrients. Diets should be balanced to attain optimal use and minimize fecal excretion of dietary nutrients. Some of the nutrients excreted in swine manure are harmful to the environment. Nitrogen (N) and Phosphorus (P) significantly contribute to environmental pollution although other minerals such as calcium, potassium, copper, zinc, cadmium and lead are also hazardous (Jongbloed and Lenis, 1998). Not all nutrients supplied in the feed are absorbed, athough some are utilized less efficiently because they exceed the Corresponding Author: Ondieki Gekara, Department of Agriculture, University of Arkansas at Pine Bluff, Pine Bluff, Arkansas, US

amounts needed by the animal (Torrallardona, 1999). Usually only 20 to $50 \%$ of $\mathrm{N}$ and 20 to $60 \%$ of $\mathrm{P}$ consumed is retained in the body; the rest is excreted in urine and feces (Pee-Schwering et al., 1999) with majority of the excretion occuring through the feces.

Safe disposal of manure with minimum effect on the environment is a major problem facing intensive swine production. Manure generated this way is usually applied in crop and pasture fields in place of synthentic fertilizers. However, excessive manure application may result in mineral overload in the soil and cause an imbalance between soil availability and plant use to meet requirements (Aarnink and Verstegen, 2007). Consequently, excessive amounts of $\mathrm{N}$ and $\mathrm{P}$ accumulate 
in the soil and this may cause an overload problem for the environment. Furthermore, surplus $\mathrm{N}$ in manure leaches into ground and surface waters resulting in high nitrate levels in ground water whereas surplus $\mathrm{P}$ through runoff and erosion can cause eutrophication of surface water. Modification of animal diets to include only the amount of $\mathrm{N}$ and $\mathrm{P}$ that the animal needs has shown potential to reduce the excretion of $\mathrm{N}$ and $\mathrm{P}$ (Aarnink and Verstegen, 2007; Cole et al., 2003; Sutton et al., 1999). Literature is lacking on the effect of replacing all corn with brewers rice in diets for growing-finishing pigs on animal performance and carcass quality.

Our research focused on reducing fecal loss of $\mathrm{N}$ and $\mathrm{P}$ in growing-finishing pigs because this is the stage when amounts of manure excreted are at their highest levels because of the large number and size of pigs raised within this class. Thus, we hypothesized that diet modification that includes the select use of certain energy, $\mathrm{N}$ and $\mathrm{P}$ sources will increase Apparent Total Tract Digestibility (ATTD) of nutrients and reduce fecal output and loss of $\mathrm{N}$ and $\mathrm{P}$ in the feces without effect on performance and carcass quality of growing-finishing pigs. Consequently, the objectives of this study were to determine the effect of diet modification on; (1) fecal excretion of $\mathrm{N}$ and $\mathrm{P}$ and (2) animal performance and carcass quality of growing-finishing pigs.

\section{MATERIALS AND METHODS}

This study was conducted at the University of Arkansas Pine Bluff (UAPB), Pine Bluff Farm, in between March 15, 2012 and April 15, 2012 and lasted 32 days.

\subsection{Experimental Design, Housing and Animals}

Growing-finishing pigs were randomly assigned to diets based on body weight and sex. There were two diet treatments in this experiment, replicated four times, for a total of eight pens. There were two animals per replicate for a total of sixteen animals. The animals were housed in semi-open concrete floor pens each measuring $2.13 \times 6.26 \mathrm{~m}(2.13 \times 2.13 \mathrm{~m}$ portion is under roof).

Experimental animals were managed to meet the recommendations of the UAPB Institutional Animal Care and Use Committee. Animals used in this experiment were approximately $3 / 4$ Yorkshire $\mathrm{x} 1 / 8$ Duroc $\mathrm{x} 1 / 8$ Hampshire crosses. Average Body Weight (BW) of the pigs on day 0 of the study was $77 \pm 2.5 \mathrm{~kg}$. All animals used in this study were born and raised on the UAPB Farm. Prior to the animals being placed on the study, they were housed together on a concrete-floor growing unit with similar design of outside and inside pens. During their growing phase, the animals were fed a corn based commercial grower diet. The pigs were a mixed group of barrows and gilts. The pigs stayed in their respective pens throughout the experimental period except when they were removed for weighing and other data collections. There was no death, sickness or disease among these pigs during the experimental period.

\subsection{Diets}

All diets were mixed at the UAPB Farm. Most of the ingredients used in mixing the experimental diets were sourced locally. Corn, brewers rice and alfalfa pellets were ground before mixing to facilitate a homogenous feed mixture and also to increase their use.The treatment diets were: (1) Corn/Soybean Meal (CSM; control); and (2) Brewers Rice/Soybean Meal (RSM). All diets were formulated to contain 14\% CP. Phosphorus level was approximately the same across diets. Feed was weighed and fed manually to the animals daily at $0900 \mathrm{~h}$. Daily feed amounts offered were based on the daily nutrient requirements for growing-finishing pigs following the National Research Council (NRC) recommendations (NRC, 2012). Animals were limit fed at $2.7 \%$ of $\mathrm{BW}$ on a DM basis. Feed intake at this level was calculated to supply adequate nutrients to support maintenance and growth i.e., Average Daily Gain (ADG). In feed restriction, we were interested in minimizing loss of $\mathrm{N}$ and $\mathrm{P}$ in the feces by lowering intake while not compromising animal performance. The feed amounts were adjusted midway through the experimental period, to match changing animal needs due to increased growth. Drinking water was provided at all times via wall mounted nipple drinkers. Soybean meal was used as the main protein source (Table 1).

\subsection{Variables Measured}

Variables determined included: ADG, ATTD, feed N and $\mathrm{P}$, fecal $\mathrm{DM}$ output, fecal $\mathrm{N}$ and $\mathrm{P}$, gain to feed ratio (G:F), cost/kg of ADG, Back Fat Thickness (BFT), carcass yield, Loin Eye Area (LEA) and fat depth. To determine ADG, animals were weighed at the start (day 0), middle (day 15) and end (day 32). The ATTD of dietary N and P was the calculated percent difference between intake $\mathrm{N}$ and $\mathrm{P}$ and fecal $\mathrm{N}$ and $\mathrm{P}$, on a DM basis. 
Table 1. Composition of experimental diets

\begin{tabular}{lcc} 
& \multicolumn{2}{c}{ Experimental Diet $^{1}$} \\
& ------- & \multicolumn{1}{c}{ RSM } \\
\hline Item & - & 76.80 \\
Brewers rice, \% & 78.20 & - \\
Corn, dented yellow, \% & 10.00 & 13.60 \\
Soybean meal, \% & 8.15 & 5.60 \\
Alfalfa pellets, \% & - & - \\
Dried distillers brewer's yeast, \% & 2.45 & 2.15 \\
Dicalcium phosphate, \% & 0.75 & 1.80 \\
Limestone, \% & 0.20 & 0.20 \\
Salt, \% & 0.25 & 0.25 \\
Mineral/vitamin premix ${ }^{2}, \%$ & & \\
Nutrient composition (calculated) & 3018.00 & 2730.00 \\
ME, kcal/kg & 14.03 & 14.03 \\
CP, \% & 0.79 & 0.75 \\
P, \% & 0.99 & 0.90 \\
Ca, \% & 0.56 & 0.76 \\
Lys, \% & & \\
Nutrient composition (analyzed) & 1.86 & 2.33 \\
N, \% & 0.60 & 0.86 \\
P, \% & 10.50 & 2.73 \\
NDF, \% & 4.94 & 2.85 \\
ADF, \% & 5.63 & 5.70 \\
Ash, \% & &
\end{tabular}

${ }^{\mathrm{T}}$ Treatments: $\mathrm{CSM}=$ corn/soybean meal; RSM = brewers rice/soybean meal; ${ }^{2}$ Mineral/vitamin premix provided per kilogram: iron, 180 ppm; zinc, 180 ppm; manganese, 37 ppm; copper, $75 \mathrm{ppm}$; iodine, $2.5 \mathrm{ppm}$; selenium, $1.5 \mathrm{ppm}$; vitamin A, 15,000 IU; vitamin $\mathrm{D}_{3}, 2,500 \mathrm{IU}$; vitamin $\mathrm{E}, 60 \mathrm{IU}$; vitamin $\mathrm{B}_{12}, 62 \mu \mathrm{g}$; menadione, $2.5 \mathrm{mg}$; riboflavin, $13.7 \mathrm{mg}$; Dpantothenic acid, $102.5 \mathrm{mg}$

The fecal loss of $\mathrm{N}$ and $\mathrm{P}$ was calculated from average fecal output excreted during the last four days of the sampling period. Fecal DM output was determined by multiplying the average total feces collected by the DM percent of each fecal sample. Feed, fecal DM and N were analyzed according to procedures described by Horwitz (2000). Feed and fecal $\mathrm{N}$ was determined using the Kjeldahl method. This is a standard analytical method that is used to determine the concentration of $\mathrm{N}$ in a given sample. Feed and fecal samples were dried and ground to pass through a $2 \mathrm{~mm}$ screen using the Wiley mill (Thomas Scientific, Swedesboro, NJ). Ground samples from four sampling days were composited into one sample each. Composite fecal and feed samples were analyzed for DM, N, P, Neutral Detergent Fiber (NDF), Acid Detergent Fiber (ADF) and ash.

Feed and fecal samples were also sent to an outside laboratory for N (verification) and P analysis. Samples for P analysis were digested in nitric acid $\left(\mathrm{HNO}_{3}\right)$ on a hot block heated to more than $60^{\circ} \mathrm{C}$ for up to $1 \frac{1}{2}$ hours depending on sample. Appearance of reddish smoke signaled that initial digestion was complete. Hydrogen Peroxide $\left(\mathrm{H}_{2} \mathrm{O}_{2}\right)$ was added at this point and further digestion allowed to continue until about $5 \mathrm{~mL}$ of sample was left in the tube. The digested solution was diluted to bring the volume to $25 \mathrm{~mL}$. The diluted sample was run through the Individually Coupled Plasma Emission Spectroscopy (ICP-AES) analyzer for final determination of $\mathrm{P}$ concentration.

\subsection{Sampling Procedures}

Experimental animals were weighed at the start (day 0), day 15 and end of the experiment (day 32). Back Fat Thickness (BFT) was measured on each experimental animal at weighing. The BFT was measured using a hand held ultra sound machine (Renco Lean Meater ${ }^{\circledR}$, Minneapolis, MN). Gain to feed ratio (G: F) was calculated from $\mathrm{ADG}$ and feed DM intake values. Cost of gain was an estimate of the cost (feeds, labor) of gaining one $\mathrm{kg}$ of BW.

\subsection{Fecal Collection and Feed Sampling}

Total feces were collected within each pen during the last four days of experiment (day 29, 30, 31 and 32). The feces were collected at the same time every collection day, in numerical order starting with the same pen. All feces was gathered and placed in a bucket. The buckets were pre-weighed and marked by pen before filling them with the feces. Once the weight was determined, feces were mixed within the bucket and a sub-sample collected for laboratory analysis. The fecal sub-samples were stored in a freezer at $-20^{\circ} \mathrm{C}$, until further laboratory analysis. During the sampling period the pens were not allowed to be washed down. This was to ensure that everything excreted by the pigs during the sampling period was collected. Each batch of mixed feed was sampled at the end of each mixing. Sub-samples of each feed were placed in a bag and stored in a freezer at $-20^{\circ} \mathrm{C}$, until further lab analysis.

\subsection{Carcass Yield}

At the conclusion of the experiment, one pig per pen was randomly selected for slaughter at a nearby USDA inspected slaughter facility, to obtain carcass data. Carcass data determined were carcass yield, LEA and fat depth. Carcass yield was a calculated percent of carcass weight divided by pig BW at slaughter. Once the slaughter facility was finished with slaughter of the pigs and consequent carcass inspection, the carcasses were weighed and packed before being transported back to UAPB for further carcass evaluation. The 10th rib was removed to facilitate measurement of the LEA and fat depth. The LEA was determined using the loin eye grid. Fat depth was measured along the side of the 10 th rib muscle. 


\subsection{Statistical Analysis}

Data were analyzed as a randomized complete block design, with pen comprising of two pigs as the experimental unit and block based on initial pig BW. All data were subjected to Analysis of Variance (ANOVA) generated using the GLM procedures of SAS (SAS Inst. Inc., Cary, NC). The error term of pen within diet was used to test the effect of treatments on response variables (animal performance and carcass quality data). Treatment differences were considered significant at $\mathrm{p}<0.05$. When a significant $\mathrm{F}$-value for treatment means $(p<0.05)$ was observed in the ANOVA, it meant that it was compared using the least significant difference.

\section{RESULTS}

Compared to pigs finished on the CSM diet, pigs finished on the RSM diet gained faster (Table 2; $\mathrm{p}<0.01)$. Pigs finished on the RSM diet had a lower $(\mathrm{p}<0.001)$ fecal DM output compared to pigs fed on the CSM diet. Consequently, pigs fed the RSM diet had the greater $(p<0.001)$ ATTD than the CSM pigs. Response to dietary $\mathrm{P}$ was somewhat different; pigs finished on the RSM diet had lower loss of dietary P compared to pigs fed the CSM diet (Table 3).

Results also showed a higher digestibility $(\mathrm{p}<0.01)$ of $\mathrm{N}$ and $\mathrm{P}$ for pigs fed the RSM diet compared to the CSM pigs.

Table 2. Effect of replacing corn with brewers rice on ADG, fecal output, apparent total tract digestibility, feed efficiency and cost of gain by growing-finishing pigs

\begin{tabular}{|c|c|c|c|c|}
\hline Variable & $\mathrm{CSM}^{1}$ & RSM & SEM & P value \\
\hline BW at start, kg & 74.830 & 78.628 & 2.531 & $>0.100$ \\
\hline $\mathrm{BW}$ at end, $\mathrm{kg}$ & 93.424 & 101.420 & 2.713 & $<0.010$ \\
\hline DM intake, $\mathrm{kg}$ & 2.029 & 2.029 & 0.000 & \\
\hline $\mathrm{ADG}, \mathrm{kg}$ & 0.581 & 0.712 & 0.041 & $<0.010$ \\
\hline $\mathrm{FO}^{2}, \mathrm{~kg}$ & 0.322 & 0.171 & 0.093 & $<0.001$ \\
\hline ATTD $^{3}, \%$ & 84.100 & 91.500 & 3.217 & $<0.001$ \\
\hline $\mathrm{G}: \mathrm{F}^{4}, \mathrm{~kg} / \mathrm{kg}$ & 0.286 & 0.351 & 0.014 & $<0.010$ \\
\hline Cost of gain, $\$ / \mathrm{kg}$ & 1.642 & 1.071 & 0.085 & $<0.050$ \\
\hline
\end{tabular}

${ }^{1} \mathrm{CSM}=$ corn/soybean meal; RSM = brewers rice/soybean meal; ${ }^{2} \mathrm{FO}=$ fecal output (dry matter); ${ }^{3} \mathrm{ATTD}=$ apparent total tract digestibility; ${ }^{4} \mathrm{G}: \mathrm{F}=$ gain to feed ratio

Table 3. Effect of replacing corn with brewers rice on intake, fecal $\mathrm{N}$ and $\mathrm{P}$ and digestibility of $\mathrm{N}$ and $\mathrm{P}$ in growing-finishing pigs

\begin{tabular}{lcccc}
\hline Variable & CSM $^{1}$ & RSM & SEM & P value \\
\hline Intake N, kg & 0.046 & 0.138 & 0.001 & $<0.001$ \\
Intake P, kg & 0.011 & 0.011 & 0.000 & $>0.100$ \\
Fecal N, kg & 0.011 & 0.007 & 0.001 & $<0.001$ \\
Fecal P, kg & 0.008 & 0.007 & 0.002 & $<0.001$ \\
Digest N, \% & 76.682 & 87.915 & 2.770 & $<0.001$ \\
Digest P, \% & 27.413 & 39.810 & 3.634 & $<0.001$ \\
\hline
\end{tabular}

${ }^{\mathrm{T}} \mathrm{CSM}=$ corn/soybean meal; RSM = brewers rice/soybean meal

Table 4. Effect of replacing corn with brewers rice on the back fat thickness and carcass quality of growing-finishing pigs

\begin{tabular}{|c|c|c|c|c|}
\hline Variable & $\mathrm{CSM}^{1}$ & RSM & SEM & $\mathrm{P}$ value \\
\hline $\mathrm{BFT}^{2} 11, \mathrm{~mm}$ & 8.125 & 8.125 & 0.375 & $>0.10$ \\
\hline $\mathrm{BFT}^{2} 12, \mathrm{~mm}$ & 7.750 & 9.250 & 0.354 & $>0.10$ \\
\hline BFT 21, mm & 19.375 & 20.750 & 1.105 & $>0.10$ \\
\hline BFT $22, \mathrm{~mm}$ & 20.125 & 24.000 & 1.226 & $<0.05$ \\
\hline $\mathrm{BFT}^{3} 1$ change, $\mathrm{mm}$ & -0.375 & 1.125 & 0.315 & $<0.10$ \\
\hline BFT 2 change, $\mathrm{mm}$ & 0.750 & 3.250 & 0.966 & $<0.10$ \\
\hline Carcass yield, \% & 76.548 & 73.774 & 1.288 & $>0.10$ \\
\hline $\mathrm{LEA}^{4}, \mathrm{~cm}^{2}$ & 35.805 & 42.338 & 2.756 & $>0.10$ \\
\hline Fat depth, cm & 2.478 & 2.795 & 0.186 & $>0.10$ \\
\hline
\end{tabular}

${ }^{1} \mathrm{CSM}=$ corn/soybean meal; RSM = brewers rice/soybean meal; ${ }^{2}$ BFT 11 = back fat thickness (layer 1 period 1); BFT $12=$ back fat thickness (layer 1 period 2); BFT 21 = back fat thickness (layer 2 period 1); BFT 22 = back fat thickness (layer 2 period 2 ); ${ }^{3}$ BFT 1 change $=32$-day fat accumulation for fat layer 1 ; BFT 2 change $=32$-day fat accumulation for 2 fat layers; ${ }^{4}$ LEA $=$ loin eye area 
Diet had no effect $(\mathrm{p}>0.10)$ on carcass quality i.e., carcass yield, LEA and fat depth (Table 4). Although diet had no effect on back fat thickness for layer 1, pigs fed the RSM diet tended $(p<0.10)$ to lay more fat in layer 2 compared to the CSM pigs (Table 4).

\section{DISCUSSION}

Pigs fed the RSM diet had a greater reduction in fecal DM output probably due to a lower NDF and ADF level in the RSM diet (Table 1) compared to the CSM diet. Fiber content has an inverse relationship with digestibility and this probably explains why the CSM diet with higher fiber content was less digested compared with the RSM diet. Greater ATTD for the RSM diet meant that less feces was excreted compared to the CSM diet.

The significant reduction in the fecal loss of $\mathrm{N}$ and $\mathrm{P}$ may have been due to differences in ATTD and, dietary $\mathrm{NDF}$ and ADF. The RSM diet had a greater $\mathrm{N}$ and $\mathrm{P}$ digestibility and lower levels of NDF and ADF compared with the CSM diet. Fiber (mainly ADF) and digestibility are negatively correlated, thus, the significantly lower ADF levels in the RSM diet compared with the CSM diet probably explains the corresponding differences in animal response. Furthermore, a more favorable $\mathrm{N}$ to $\mathrm{P}$ ratio (Bjorck et al., 1994; French, 1973) in the RSM diet (mainly attributed to brewers rice) compared with the CSM diet (mainly attributed to corn) may have resulted in greater digestibility and lower excretion of $\mathrm{N}$ and $\mathrm{P}$ in the feces.

In addition, greater ATTD for the RSM fed pigs compared to the CSM fed pigs can be attributed to differences in the concentration of Non-Starch Polysaccharides (NSP), mainly the cell wall carbohydrates, Resistant Starch (RS) to amylase digestion and other complexes (Brown, 1996; Englyst et al., 1992; Gallant et al., 1992). The RSM diet probably had a lower amylose (Goddard et al., 1984), NSP and RS (Berry, 1986) concentration making the diet more digestible than the CSM diet. Regular rice contains about $20 \%$ amylose and thus less RS, compared to more than $25 \%$ for corn (Bjorck et al., 1994; Rooney and Pflugfelder, 1986).

A better gain to feed ratio for pigs fed the RSM diet compared with the CSM pigs may have been due to greater ADG since feed intake was the same across diets. Although intake of $\mathrm{N}$ and $\mathrm{P}$ was greater for pigs fed the RSM diet, pigs fed the CSM diet excreted more $\mathrm{N}$ and $\mathrm{P}$ in the feces, suggesting that dietary $\mathrm{N}$ and $\mathrm{P}$ were bound to NSP more in the CSM diet than in the RSM diet.

\section{CONCLUSION}

Brewers rice replaced all corn in diets for growingfinishing pigs without having any adverse effects on animal performance. In addition, pigs fed brewers rice based diet used $\mathrm{N}$ and $\mathrm{P}$ more efficiently as demonstrated by a greater reduction in the fecal excretion of these nutrients. Thus, brewers rice is a suitable alternative to corn for finishing pigs in regions where it is in abundant supply.

\subsection{Implications}

Diet modification that involved the use of brewers rice in place of corn may have resulted in greater $\mathrm{N}$ and $\mathrm{P}$ being digested. Thus, brewers rice based diets may have provided animals with highly digestible nutrients and this may have contributed to a reduction in the fecal excretion of $\mathrm{N}$ and P. Further research should determine the eating attributes and fat profile of carcasses harvested from pigs finished on brewers rice based diets compared to corn based diets. Future research should determine the extent of $\mathrm{N}$ and $\mathrm{P}$ bound to non-starch polysaccharises and how this affects availability of dietary $\mathrm{N}$ and $\mathrm{P}$ relative to utilization in swine.

\section{REFERENCES}

Aarnink, A.J.A. and M.W.A. Verstegen, 2007. Nutrition, key factor to reduce environmental load from pig production. Livestock Sci., 109: 194-203. DOI: 10.1016/j.livsci.2007.01.112

Berry, C.S., 1986. Resistant research: Formation and measurement of starch that survives exhaustive digestion with amylolytic enzymes during the determination of dietary fiber. J. Cereal Sci., 4:301314. DOI: $10.1016 /$ S0733-5210(86)80034-0

Bjorck, I., Y. Granfeldt, H. Liljberg, T. Tovar and N.G. Asp, 1994. Food properties affecting the digestion and absorption of carbohydrates. Am J. Clin. Nutr. 59: 699S-705S. PMID: 8116553

Brown, I., 1996. Complex carbohydrates and resistant starch. Nutr. Rev., 54: S115-S119. DOI: 10.1111/j.1753-4887.1996.tb03830.x

Cole, N.A., L.W. Greene, F.T. McCollum, T. Montgomery and K. McBride, 2003. Influence of oscillating dietary crude protein concentration on performance, acid-base balance and nitrogen excretion of steers. J. Anim. Sci., 81: 2660-2668. PMID: 14601868 
Englyst, H.N., S.M. Kingman and J.H. Cummings, 1992. Classification and measurement of nutritionally important starch fractions. Eur. J. Clin. Nutr., 2: 533-550. PMID: 1330528

French, D., 1973. Chemical and physical properties of starch. J. Anim. Sci., 37: 1048-1061. PMID: 4583690

Gallant, D.J., B. Bouchet, A. Buleon and S. Perez, 1992. Physical characteristics of starch granules and susceptibility to enzymatic degradation. Eur. J. Clin. Nutr., 46: S3-S16. PMID: 1330527

Goddard, M.S., G. Young and R. Marcus, 1984. The effect of amylose content on insulin and glucose responses to ingested rice. Am. J. Clin. Nutr., 39: 388-392. PMID: 6364775

Horwitz, W., 2000. Official Methods of Analysis. 17th Edn., Association of Official Analytical Chemists, Arlington, ISBN-10: 0935584242.

Jongbloed, A.W. and N.P. Lenis, 1998. Environmental concerns about animal manure. J. Anim. Sci. 76: 2641-2648. PMID: 9814905
Pee-Schwering, C.M.C. Van Der, A.W. Jongbloed and A.J. Aamink, 1999. Nitrogen and phosphorus consumption, utilization and losses in pig production: The Netherlands. Livest. Prod. Sci., 58: 213-224. DOI: 10.1016/S0301-6226(99)00010-X

Rooney, L.W. and R.L. Pflugfelder, 1986. Factors affecting starch digestibility with special emphasis on sorghum and corn. J. Anim. Sci. 63: 1607-1623. PMID: 3539904

NRC, 2012. Nutrient Requirements of Swine. 11th Edn., National Academies Press, Washington, ISBN-10: 0309224233

Sutton, A.L., K.B. Kephart, M.W. Verstegen, T.T. Canh and P.J. Hobbs, 1999. Potential for reduction of odorous compounds in swine manure through diet modification. J. Anim. Sci., 77: 430-439. PMID: 10100673

Torrallardona, D., 1999. Reduction of nitrogen excretion in pigs. Improvement of precision in nutrient requirements. Cah. Opt. Mediterr, 37: 265-274. 